\title{
Participation of Women in Development of Community Radio
}

\author{
Dr. Sapna.M.S ${ }^{1^{*}}$, Rakesh.C ${ }^{2}$ \\ ${ }^{1}$ Associate Professor, Dept of Journalism and Communication, University of Mysore, Mysore \\ ${ }^{2}$ Research Scholar, Dept of Journalism and Communication, University of Mysore, Mysore
}

*Corresponding Author: Dr. Sapna.M.S, Associate Professor, Dept of Journalism and Communication, University of Mysore, Mysore

\begin{abstract}
Community radio in our country is a boon to many of the communities it enables many of the vulnerable people in these communities to participate in the decision making activities which can bring in a constructive change in the matters of the community. This very dynamic medium has been extensively used in many of the remote places of the country by various communities to educate, influence and evolve themselves to form a better tomorrow. This voluntarily medium, has been attracting the members of the remote areas in a big way. In a developing country like ours, where rural populace stills lacks basic education, awareness and involvement, this Community radio has given a fresh lease of life to many to sustain themselves in all spheres of their lives. It has helped the civil societies to move towards self sufficiency and also retaining the best in the communities through the array of programs which are conceptualised and presented by the community members only. It has really played a pivotal role at the grass root level which is emulated in other countries too. Community radio, has become a crusader in the lives of many across the country, this medium which has been supported by the community it serves, has emerged in a big way in developing countries. Other Voices (Kanchan Malik and Vindod Pawarala, 2007) has assessed the role of this alternative media as on eof the best tool for the communities and the underprivileged at the grassroots level. It has become a window for the remotest communities to integrate themselves into global economies and also develop as knowledge based economies. It has been playing a great role as a force multiplier in effective delivery of programs needed for the community on all development sectors. Each and every station has a great role in conceptualizing and executing these programs which has to come from the community members only. The indulgence of the members and to sustain themselves in running the station is a uphill task. Trainings imparted by the government and funding agencies at the various level has been instrumental in its popularity. The community radio stations in the country has been facing a lot of difficulties in sustaining themselves once they are established. The support and the encouragement of this station keep losing the fizz after few years of their inception. Many reasons has been identified such as lack of technical inputs, lack of creativity, financial crisis, lack of encouragement from the community, diminishing participation of members and so on. But, still, there are many CR stations which have proved and stood all the odds by proving their capacity to perform and bring in the change. Such CR stations are those which are under the leadership of women, who have given their best to sustain in the race by facing all the problems and overcoming it. The present paper, tries to focuses on the participation of women, with such positive outlook, who have driven the medium to a next level, in the development of community radio stations. The study has been done in the state of Karnataka, which has 13 CR stations. A multiple sampling technique has been used to select the best 4 community radio stations for the study. Keeping in view the gender perspective, the study highlights and dwell upon the role of women, in particular in the development of these community radio stations. The key roles played by the women as station managers, the content developers, the presenters and as listeners has been investigated through a systematic Focus group discussion, which has helped to elicit the information by these duty bearers. The role play of these women in the community radio has been very promising, and not only they contribute but also strive hard for the development of CR stations in the areas of their operations. The women members have been doing various experiments in the content and output which has not only yielded positive side of the medium, but also has empowered these women employees to do more though this medium. The result has been positive and thus many of them feel that the CR has become a integral part of their life and can has been instrumental in making their life more empowered. The study establishes that these community radio has worked in favour of these women to improve knowledge of solutions, in areas like health and hygiene, culture retention, rural development, participation in democratic process, education to local governance, employment opportunities and awareness related to social taboos.
\end{abstract}

Keywords: Community Radio, Women, Participation, Empowerment, Role play, Catalyst 


\section{INTRODUCTION}

Development, as far as concerned is a wholesome process, looking it from a micro level it refers to the change from the simple form of production and organization to the complex modern ones. Development doesn't merely means economic one, but it also refers to social, cultural, spiritual, and moral enhancements in the society as a whole. Media today has a greater role to play in bringing changes in the thought processing of the people which lead to their overall development. The traditional media has always been hegemonic in nature and thus the marginalised communities needed a way out in which free media can be provided to place their challenges where their opinions are free of fear and control and represent a true public sphere. Thus, the role of community radio in India plays a role of a catalyst in bringing a change in the communities and among people within which it operates. According to the famous community media activist Alfanso Dagron, development communication is "people taking into their hands the communication processes" making their "voices heard", establishing "horizontal dialogues" with decision-makers on matters affecting their lives to "ultimately achieve social changes" for their own benefits (Dagron 2009), The need for the participation of community for its development in all the stages was realised widely in the late 1970s. But, its not be recognized sufficiently that participation and communication are the two sides of the same coin. Mere creating the communication process where in community members participate and analytically discuss issues which can bring in change and affect their lives is more important. Community Media, particularly radio has a tremendous potential to provide the platform for community dialogue, through which people can define who they are, what they need and how to get it and at the same time can build a long term capacity to solve their problems in a constructive way which can lead to sustainable development.

\subsection{Community Radio in Global Context}

There is a huge discussion related to the impact of globalization on various culture due to the commercialization, and media plays a important role in imparting this trend. Global media plays a significant role in the promoting standards through its programs which is solely entertainment, which are not going to serve the needs of the local people. They will never respond to the socio economic developments of the countries where they operate, the question of serving the marginalised, economically backward, the deprived class cannot be raised in the global media. Hence, the need of the local media is necessary and these two entities can't be compared, The former one mainly deals with the entertainment, commercialization, popular culture, where as the latter deals with issues pertaining to local language, local culture and local issues, which aims at helping the community overcome social, cultural and economic barriers.

\subsection{Importance of Community Radio}

India has been one of the leading country, which has promoted the concept of community radio for the development of communities. India has been in the forefront since the UNESCO has been actively promoting this concept as an agent of change and development. At present, India has 173 operational community radio stations spread across the length and breadth of the country. The concept of owning and operating by the community has been well received at the grassroots level which are mostly managed by communities themselves, religious organizations, or by NGOs. The major principle of community radio includes:

$>$ Local Identity: Culture is one of the backbone of the communities, Culture is what, people of the community speak about their past and future, it's their identity. Culture is infinitely variable and constantly evolving. Community cultures usually emerge out of their artistic expressions in the form of music, poetry, dance, storytelling or theatre. This helps in promoting and focussing principally on local content and gives them local identity

$>$ Diversity of Voices: Discomfort and discord will be present in all communities, but the acknowledgement of conflict is necessary for democracy and democratic communities. This medium will create diversity in voices and opinions and tries to air objectively all sides of discussion without taking stand.

$>$ Provides Forum: It provides a open forum to discuss and to encourage open dialogue by providing a independent platform for discussions and deliberations which matters to the community as a whole. It also helps in designing developmental initiatives that meets the 
aspirations of the community members

$>$ Good Governance: The marginalised and oppressed usually have no way to complain when authorities take undue advantage of them. The community radio plays the role of a watchdog that makes the politicians and local authorities more conscious about their responsibilities thus promoting good governance and a civilized society.

$>$ Promote Social Change and Development: The marginalised members have perceptions of their own on various situations. The collective perceptions can be changed only with collaborations and series of discussions to identify the issues, analyse specific problems and provide solutions by rigorous internal discussions, thus paving way for social change and development.

$>$ Encouragement: Other important functions also include, empowering women folk for participation, exchange of innovations and ideas, providing guidance and social services whenever required.

\subsection{Importance of this Medium}

This medium plays a greater role in serving the geographic communities and community needs , These station which are operated, managed and owned by the community members serve on a non profit basis and provides a mechanism for individuals in facilitating to tell their own stories, experiences which may not interests the commercial broadcasters. Walter et al (2011) assessed the importance of community radio stations in Indonesia and concluded that effective radio activities can make a significant change in the community lives. The exchange of ideas and information, networking of groups, the provision of skills and training and these undoubtedly are key elements of developing a community. Again, a radio facility for a community accelerate the promotion of awareness of groups and facilities in the area as well as providing the possibility for the empowerment of these groups to use radio to promote themselves and to speak directly to the community

\subsection{Community Radio Status in India}

Even after 62 year of independence, Indian society has many deep rooted issues which needs attention to be eradicated. Though the country has achieved tremendously in the field of science and technology, defence forces, space technology, educational spheres etc, but still much more needs to be done for the development of the society as a whole. The population of the country has been multiplied at an alarming speed and the resources remain the same. The major issues, such as poverty, illiteracy, unemployment are growing day by day .Besides, economic development too has taken a back seat. Government is taking various steps to develop the various sections to accomplish anything under the given scenario. With more than $70 \%$ of the population dwelling in the rural areas, it has become very necessary to empower them in all sectors. With huge amount being pumped into the various projects related to rural development. The government has realised the importance of rural upliftment in order to improvise the rural conditions. Though the government is spending large amount but with minimal results, the reason behind this may be many reason such as communication, unexpected issues of transferring information, lack of knowledge, lapses in implementation program, communication gap between government devised policies and general masses and so on . Many of the programs remains unutilised at the rural level and communities stay unaware of those benefits. In order to bridge this gap a firm communication policies will prove very crucial. According to this, local community media needs to be promoted in order to see development at the grassroots level. Among the existing local community media, community radio, has proved to be more timely, useful and effective and more cheaper way of convincing the community members for a larger benefit.

Many studies related to the community radio across the globe in developing countries have proved that the provision of information and skill can gain popularity in the quest of empowering the communities, Kumar (2004) identified radio as an avenue for participatory communication and as a tool relevant in both economic and social development and Chapman et al (2003) reported that the growth of rural radio stations reflects both the improvements in information technologies and the shifting of development paradigm towards a more participatory style of information and knowledge transfer.

\section{WOMEN EMPOWERMENT}

Half of the population in India are women, though the status of women in our country is changing at a 
faster pace, we cannot ignore the continued existence of a world, wherein they are still discriminated, marginalized, and oppressed because of their gender. Women, have a greater role in the development process of a country, and this can be possible only when they are more opportunity and inclusion of women all development process. A proper status of women in a society is a transmitter of culture in all societies. Empowerment is a transition period from a position of enforced powerlessness to one of power. Woman empowerment is a process that enables a powerless woman to develop freedom, confidence and self control and with a group of women and men, a sense of collective influence over oppressive social conditions," noted Kumar and Varghese (2005) It promotes women's strengths and positive self-image. Gaining power means acquiring the ability and opportunity to participate and contribute in the social development process meaningfully and creatively. The process of empowerment enables her to develop in them self-dignity. It enables them to raise voice, be vocal and fight against suppression, injustice, exploitation, abuse, and violence done to them. Enjoying a powerful role in the society makes a woman empowered. Empowerment literally means "making someone powerful, facilitating the weak to attain strength, to increase one's self-esteem, to help someone to be assertive/ self-confident, to enable someone to confront injustice and oppression and to support someone to fight for her rights.

\section{COMMUNITY RADIO AND WOMEN PARTICIPATION}

One of the most difficult tasks is to achieve empowerment of women, the resistance from family members, community has always disempowered women mentality. There is a need to strategise and develop a special need to empower this fair sex in the society. Various methods such as training, education, entrepreneurship, and mentoring, feminist movements have been tried but still in vain. The media outlets have a social responsibility to provide wider platform in creating, eradicating and preserving the identity of women. From the beginning All India Radio (AIR), has been developing the programs, to inform, educate and enlighten the women folk by designing tailored made programs which can serve and promote the women. With the introduction of the CR policy guidelines in 2006, to establish community radio for the welfare of the communities, and indirectly the development of women was highlighted to a larger extent. The country has seen, many CR where the participation of the women has made it possible to be one of the best catalysts of change for the welfare of communities. CR stations Namma Dwani( Our voices), Sangam Radio, Radio Namaskar, Manndeshi Tarang are a few to be named who have been constantly working towards the empowerment of women using this medium, making them a participant, listeners, activists and a contributor. The women contribution to the popularity of the CR in our country cannot be swept aside as many of them are being operational and running successfully is due to the efforts made by the women folk of the communities.

The paper has tried to analyse the participation of women in the selected CR stations in the state of Karnataka. The objective was to find their role, responsibilities and to find out how this CR medium has played a key role empowering the women folk in their communities.

\subsection{Theoretical Framework}

The present study which is both qualitative and quantitative in nature and the present study have adopted Uses and Gratification theory of Denial McQuail (1969) where it seeks to understand, why people seek out the media that they do and what they use it for. Uses and Gratification theory differs from other media effect theories in that it assumes that individuals have power over their media usage, rather than positioning individuals as passive consumers of media.

\section{Methodology}

This study was carried out as an in depth evaluation using a participatory approach, where in it involved series of field visits and desk work. Series of studies across the country have been reviewed in the desk activities. The specific data collection from the only women respondents included series of interviews, Focus Group Discussions (FGD), meetings with stake holders, observations and debriefing sessions. The 4 community radio stations are JanaDwani, Radio Siddhartha, Radio Ninanda, and Radio Active. Each CR selected for the study are placed in different part of the state, The main idea was to get variations in terms of social, economic, political and cultural streams . Involvement of women in the activities of $\mathrm{CR}$ from different regions and kinds of issues they broadcast in the stations and its effects on listeners especially women. A In depth interaction with the 
members of the community radio members, script writers, announcers, listeners, CR managers who were all women was done with a time span of 3 months. 1 FGD was conducted among the women listeners in all 4 radio station the list of women role at various capacities has been shown in Fig 1

\begin{tabular}{|l|l|}
\hline \multicolumn{1}{|c|}{ Positions } & \multicolumn{1}{c|}{ In numbers } \\
\hline 1. Station In charge & 4 \\
\hline 2. Announcers & 7 \\
\hline 3. Program Producers & 6 \\
\hline 4. Technical Personnel's & 5 \\
\hline 5. Script Writers & 10 \\
\hline 6. Listeners & 48 \\
\hline TOTAL & 80 \\
\hline
\end{tabular}

\section{FINDINGS}

\subsection{Increase in Involvement of Community Development}

The women respondents of the selected CR have opined that the establishment of CR in their community has been a lease of fresh air .The members are feeling the attachment towards the community activities which was otherwise neglected. The CR has provided them a freedom to air issues of the community which were neglected in the past .In the milieu of making stories and content the women respondents have felt that they are voluntarily involving themselves in the community issues, thus making their presence and decisions felt in resolving them to a greater extent.

\subsection{Local Governance Issues}

The respondents feel that the radio has been a appropriate medium to create a medium to felicitate an interface with the government officials and the beneficiaries. The interactive sessions between the authorities and community members has yielded better results in the recent past. Schemes and issues pertaining to women and children's are exclusively broadcasted on regular intervals which has benefitted them in a large scale. Many women listeners feel that the CR has made it more transparent and accountable for all the political leaders to be answerable to their duties. Women members feel that they are well informed now and can raise questions when confronted by the authorities in various issues.

\subsection{Information Sharing and Communication}

With the accessibility and use of community radio, the listenership among the women has seen a good leap. They confess that they tune into the programs which they which is of their choice and are able to trace programs at their convenience. The radio has become a foundations to many of the activities happening within the community, which keep them abreast of all sectors, thus educating them and helps in sharing those important issues with the fellow members of the community. The CR has provided them a new dimension, about the members and they help each other in realising their dreams through various information broadcasted. Communicating with the community has become so easy for them, they use this medium to put across new initiatives, ideas and problems which can be solved by interacting with members

\subsection{Cultural Promotion and Entertainment}

CR has established itself as one of the important institution of entertainment and cultural ambassadors. With majority of the population staying in rural part, they have exposure to TV and internet too. But the impact of radio programs has been very encouraging. The content are usually designed in consultation with the members of the community. It's always the women who take the lead and suggest better ideas for implementation. Story telling is one of the mode in which the listeners are attracted and women play a great role as presenters. The popularity of the show have been positive when there are women presenters than men. They see that women have the capability to make their listeners hold on to the program and thus are more successful. Using the local language is one the catch point of women who use colloquial terms and slangs to convey the message easily. The higher level of listenership is a sign of cultural promotion too. Entertainment and infotainment is given equal importance in all radio stations. 


\subsection{Promotes Social Solidity}

Women in the community are of the feeling that CR programs have been able to break the wall which use to divide communities in the past. A simple issue of sharing, festivity, celebrations, or opinions used to build a lot of grudge among the members. But with the time and with regular sensitization of issues discussed on these CR, the opinions and the mindset of the people has been gradually changing. Major issues related to girls' education, dowry system, alcoholism, old age rituals have undergone a sea change. Talks and discussion by the noted members of the community are able to clear the issues using their expertise. The women members usually select the best to go on air and who can influence the thought process. Thus helping them to build a constructive society as a whole. The family session is one of the most sought after program, which helps in developing a bondage among the members, the petty issues of the family, relationships, kit and kin issues, happy family agenda, religious and ethnicity conflicts are discussed elaborately thus giving a smooth finish to the coexistence and development of healthy social fabric of community members.

\subsection{Growth in Economic Activity}

The radio stations have seen a bit of economic growth in these years of their commencement. Thanks to the dedicated women station in charge who have tried their best to sustain themselves by collecting the nominal amount in the form of ads from the local advertisers which not only promote their products but also gives a wide publicity among the community members. The local artisans, such as herbal sellers, grocery shop owners, tailor shops, and local business people are convinced by the women members to place their ads in popular shows for intensifying their results .A special segments has been planned at the CR stations where 2 hours of time is dedicated to the local business and artisans to exhibit their products through the show. Thus benefitting both the parties. The women community members are the ones who exclusively use this forum and time to sell their products. Many of the women listeners feel that by doing so they can avoid the door to door selling and also popularise their Small and Medium Enterprises (SME) in a big manner within the community.

\subsection{Leadership Challenges}

The CR stations are well managed by the women in the team. They feel more liberated and have a sense of responsibility to carry forward the activities at the station. This medium has made them more vocal and is taking interest in the issues which matter to women and children are a lot. A sense of belongingness and urge to develop the stations was one of the common things which were identified in all stations. The interest in choosing the topics for discussions, selecting the timing, resource person who can be influential to change the mindset is all taken care by the women. Right from the planning, designing and executing the program, these women managers take utmost care for making the CR program a success. The weapon of communication, which can bring a change has gone well with them and can't imagine their life without its influence. The expectations are more and feel that it's here to stay for their well being. Women members have a sense of pride in running the station solely on their capabilities and interest.

\subsection{Challenges for Women in CR}

Running a CR station is not a easy task. They do find many hurdles and challenges in the process. The main issues are as the following:

- Effective coordination among the station and community members are an issue many a times

- Continuity in the leadership is also an major issue

- Influence of external environment in the form of interference is a drawback

- A technical issue faced by the radio stations which cannot be resolved by women has been a major hurdle.

- Sustaining the radio stations without minimal economic support within the community may be hindrance sometimes.

- Lack of training at regular intervals for the station employees.

- Outdated equipments and long usage of same old technology causes transmission issues, though the content are good. 
- Error in building programs around single individuals

- External disturbances may lead to failure in reaching out the programs as planned

- Duplication of work also leads to loss of interest among listeners

- Repetition of program make the listeners keep away from CR programs

- Leadership is the key in mobilizing resources, where sometimes women fail in doing so.

- Regular evaluation of the program is not done up to the mark.

- It has provided an enabled environment for a good constructive dialogue between duty bearers and right holders.

\section{CONCLUSION}

The concept of community radio has been picking up as a best medium in the rural part as a catalyst of change and empowering women folk. This no profit entity in many parts of the country provides a mechanism for facilitating groups, individuals, youth and very particularly women a sense of empowerment .And in a media rich world its very necessary to be creative and active contributors of media, and women no doubt have been able to fill in all these gap and make it workable by giving all their might to run the show and make a difference in the lives of the community members .Community radio, no doubt acts as a change vehicle for the community, agencies, civil societies, NGOs and so on. This medium has given a fresh lease of life for women to get empowered by getting more educated and keeping them informed. The issues which needs to be taken care can be rectified at the various level and can be projected as a strong tool for the overall development but women development in particular.

\section{RECOMMENDATIONS}

Community radio facilitates a good number of activities for a capacity building among the women folk. The regular exchange of information, ideas, deliberations, provision of training and skill development has undoubtedly helped the women in these regions a capable individual. Sterling el at (2007) has provided evidence that women community radio listeners are given a voice with which to respond to programming and to create programming content. The cost of excluding women from ICT for development and explored how community radio represents an opportunity for inclusion. By employing the Participatory Action Research (PAR) approach, it was found that women will be more likely to benefit from technology-mediated opportunities for development if they themselves produce information that contributes to their advancement, rather than simply consuming information provided by others. With more women in the lead, there is a huge possibility of promoting integrated rural development in all spheres, the government or $\mathrm{s}$ the funding agencies should provide extensional teaching for the women employees. Interference from the external members or from the communities should be avoided so that decision making among them can be made easier. There is also need to update and encourage the listeners club. Quality of the program can be improvised with the consultation of the listeners at regular intervals. These community radios are the reflection of the character of the community by legal status.

\section{REFERENCES}

[1] Barr A. (2005), "The contribution of Research to Community Development". Community Development Journal 40(4) 453-458

[2] Dagron A. (2001), "Making waves: stories of participatory communication for social change". New York: The Rockefeller Foundation

[3] Innovations in Community Radio , Ministry of Information and broadcasting report by CEMCA- (2014)

[4] McKay B. (2009), "Using Community Radio in Ghana to Facilitate Community Participation in Natural Resource Management", Ecqiud Novi-African Journalism Studies, 30(1), 73-93.

[5] Pavrala Vinod, Malik Kanchan, Vasuki belawadi (2010) Blurred Vision: Development Communication and Community Radio in India

[6] Rachana Saini( 2013) A Historic Perspective of Community Radio in India 
[7] Syed.S.Kazi ( 2007), Sustaining Community Radio Initiatives in India: Challenges at the grassroots

[8] Van Vlaenderen H. (2004), Community Development Research: Merging Communities of Practice. Community Development Journal; 39(2): 135-143.

[9] Yalala Nirmala ( 2015), The role of Community Radio in Empowering Women in India, Media Asia Vol 42

Citation: Dr. Sapna.M.S, Rakesh.C. "Participation of Women in Development of Community Radio". International Journal of Media, Journalism and Mass Communications (IJMJMC), vol 5, no. 3, 2019, pp. 37-44 doi: http://dx.doi.org/10.20431/2455-0043.0503004

Copyright: () 2019 Authors. This is an open-access article distributed under the terms of the Creative Commons Attribution License, which permits unrestricted use, distribution, and reproduction in any medium, provided the original author and source are credited. 